\title{
Symposium review: Reduction in oocyte developmental competence by stress is associated with alterations in mitochondrial function ${ }^{1}$
}

\author{
Zvi Roth ${ }^{2}$ \\ Department of Animal Sciences, Faculty of Agriculture, Food and Environment, the Hebrew University, Rehovot 76100, Israel
}

\begin{abstract}
Stress can affect reproductive performance of lactating cows by targeting the ovarian pool of follicles and their enclosed oocytes. Among the documented stressors are heat stress (i.e., high temperature-humidity index) as well as environmental and food toxins. Oocytes collected during the hot season are of lower quality than those collected in the winter, expressed by reduced oocyte maturation and developmental competence. A similar pattern has been reported for oocytes exposed to endocrine-disrupting chemicals. Whereas the underlying mechanism might differ among stressors, accumulating evidence suggests that stress-induced impairment of oocyte developmental competence involves alterations in mitochondrial functioning. Within the oocyte, mitochondria are involved in ATP generation, calcium homeostasis, regulation of cytoplasmic reduction-oxidation, signal transduction, and apoptosis. Summer heat stress is strongly associated with alterations in mitochondrial distribution and alterations in mitochondria membrane potential. Heat stress impairs the expression of mitochondrion-associated genes, in particular those related to mitochondrial DNA transcription and replication and encoding oxidative phosphorylation complexes for ATP production. Reduction of ATP levels below the required threshold is suggested to compromise the progression of oocyte maturation and, subsequently, embryonic development. Another mechanism associated with mitochondrial function is the increase in reactive oxygen species (ROS), which has been documented in oocytes exposed to heat stress or environmental toxicants. Oxidative phosphorylation in mitochondria is the major source of ROS. Under physiological conditions, ROS are essential for nuclear maturation; however, disequilibrium between ROS production and antioxidative capacity might lead to DNA
\end{abstract}

Received July 3, 2017.

Accepted November 20, 2017.

${ }^{1}$ Presented as part of the Physiology and Endocrinology Symposium: Mediators of Effects of Stress on Reproduction, Growth, and Lactation at the ADSA Annual Meeting, Pittsburgh, Pennsylvania, June 2017.

${ }^{2}$ Corresponding author: z.roth@mail.huji.ac.il damage and apoptosis. The current review provides new insights into the oocyte's cellular and molecular responses to stress with an emphasis on the mitochondria. It discusses some strategies to mitigate the effects of stress on the mitochondria, such as incorporation of coenzyme Q10 - a key component of the mitochondrial respiratory chain-administration of antioxidants, and injection of healthy mitochondria. Exploring the oocyte's cellular and molecular responses, in particular that of the mitochondria, might lead to the development of new strategies to mitigate the effects of various stressors on fertility.

Key words: stress, mitochondria, oocyte developmental competence

\section{INTRODUCTION}

In the 1940s, Hanse Selye defined stressor as the factor that triggers the stress response (Szabo et al., 2012). Using Selye's terminology, it is suggested that induction of stress can affect reproductive performance of lactating cows by targeting the ovarian pool of follicles and their enclosed oocytes. Among the documented stressors are environmental and metabolic factors, food toxins, and pathogens. Selye claimed that we should not define an effect as a stress response until the same effect is induced by several stressors that differ in nature (Szabo et al., 2012). It is becoming clear, however, that not all stress reactions are equal, due to the involvement of various mechanistic pathways. Nevertheless, although the underlying mechanisms might differ among stressors, accumulating evidence suggests that various stressors impair oocyte mitochondrial function.

The current review discusses the effects of 2 main environmental stressors on the oocyte, with an emphasis on the mitochondria. Within the oocyte, mitochondria are involved in ATP generation, calcium homeostasis, regulation of cytoplasmic oxidation-reduction, signal transduction, and apoptosis. Thus, stressor-induced alterations in oocyte mitochondria are suggested to affect oocyte developmental competence. The review discusses the effects of various stressors on oocyte mitochondrial features, structure, and function, in particu- 
lar the mitochondria's role in oocyte maturation and early embryonic development. The review also suggests some potential approaches to overcoming these effects. Understanding the oocyte's cellular and molecular responses might enable the development of new strategies to mitigate the effects of various stressors on the oocyte.

\section{MITOCHONDRIA}

Mitochondria are cytoplasmic organelles found in all eukaryotic cells. They generate ATP, the cell's major source of energy, and are therefore essential for various cellular functions. They are also involved in calcium signaling and apoptosis (Gunter et al., 2004). Mitochondria are composed of a double membrane. The outer membrane separates the mitochondrial matrix from the cell cytoplasm, whereas the inner membrane forms the cristae. The latter are the site of the electron transport chain where the final cellular respiration stage, oxidative phosphorylation, takes place. The electron transport chain consists of 5 enzyme complexes (I-V), each constructed from multiple polypeptide subunits. The electrons flow through the first 4 electron transport chain complexes, leading to proton release from the mitochondrial matrix into the intermembrane space and forming the mitochondria's membrane potential. Reentry of protons into the mitochondrial matrix through the 5th complex leads to ATP generation via ATP synthase (Andersson et al., 2003).

The mitochondria contain their own conserved genome [mitochondrial DNA (mtDNA)], presumably a remnant of their bacterial origin. The mtDNA is a double-stranded circular DNA molecule of approximately $16.5 \mathrm{~kb}$; it has 37 genes encoding 13 polypeptides involved in the electron transport chain, 22 transfer RNA, and 2 rRNA (Jansen, 2000). Crosstalk between the mitochondrial and nuclear DNA is highly important for mitochondrial function (Poyton and McEwen, 1996; Cannino et al., 2007). The host cell (e.g., the oocyte) depends on the mitochondrial genome for aerobic respiration, just as the mitochondria rely on proteins encoded by the oocyte's nuclear DNA. Both nuclear and mitochondrial genomes are required to form electron transport chain components, which in and of itself is a unique phenomenon.

\section{OOCYTE MITOCHONDRIA}

In mammals, the number of mitochondria increases dramatically as the oocyte grows. In cattle, a 45-fold increase in mitochondria occurs from the primordial germ cell to the preovulatory follicular stage (Smith and Alcivar, 1993), with a mean 260,000 mitochondrial copies in mature oocytes (Michaels et al., 1982). After fertilization and through the early stages of embryonic development, mitochondrial biogenesis ceases and their number remains constant until embryo implantation (Dumollard et al., 2007). Nevertheless, differences between species have been reported; mtDNA content does not change until gastrulation in fishes (Wang and Yan, 1992), before the pluteus stage in sea urchin (Matsumoto et al., 1974), before the swimming tadpole stage in frogs (Chase and Dawid, 1972), or before larval stage in nematodes (Tsang and Lemire, 2002). The mtDNA copy number is constant until implantation in the mouse (Pikó and Taylor, 1987), but in cattle mtDNA content is reduced from the 4-cell stage until the morula stage, followed by a considerable increase at the blastocyst stage (May-Panloup et al., 2005). Thus, it is very important that the oocyte have a good reserve of mitochondria to ensure an appropriate embryonic development.

Mitochondrial structure also changes in a stage-specific manner. In the ovulated oocyte, the mitochondria have a primitive structure characterized by an immature spherical shape with a dense matrix and only a few cristae (Motta et al., 2000). Through early embryonic growth, the mitochondria undergo structural transformations; namely, they adopt an elongated configuration with an extensive array of cristae and a high level of ATP production.

Mitochondrial respiration is a central determinant of developmental competence in mature and immature oocytes (St John et al., 2010; Chappel, 2013). Bioenergetic deficits that decrease net cytoplasmic ATP levels below a stage-specific threshold, approximately 1.7 to $2 \mathrm{p} M$, might compromise the progression of mouse oocyte maturation and development of preimplantation embryos (Yu et al., 2010). It should be noted that mitochondrial biogenesis stops after fertilization. Therefore, the amount of mtDNA in the mature oocyte is a rate-limiting factor for the number of electron transport chain components formed. On the other hand, human oocytes with high numbers of mitochondria are associated with high developmental competence (Van Blerkom et al., 1995).

The distribution of mitochondrial pattern within the oocyte varies during oocyte maturation in a stagedependent manner (Bavister and Squirrell, 2000). It is therefore considered a determining factor in maturation progression and fertilization competence. Oocytes with low maturation competence lack signs of mitochondrial organization or, alternatively, express larger mitochondrial clumps throughout the cytoplasm. Oocytes with large mitochondrial clumps at the cytoplasm periphery express high maturation competence (Stojkovic et al., 2001). Metaphase II (MII)-stage oocytes with highly 
polarized mitochondria in the subplasmalemma are of high developmental competence and, therefore, mitochondrial distribution pattern is suggested as a prerequisite for fertilization competence (Van Blerkom et al., 2002).

The role for high-potential mitochondria in the fertilization process is well documented; MII-stage mouse oocytes with reduced mitochondrial membrane potential are permissive for sperm binding but not for the sperm penetration, which occurs only after high mitochondrial membrane potential is restored (Van Blerkom and Davis, 2007). Mature human oocytes with scant or undetectable domains of high-potential subplasmalemmal mitochondria cannot be penetrated by sperm (Van Blerkom et al., 2002). Cryopreserved human oocytes that do not express high mitochondrial membrane potential after thawing are not penetrable (Jones et al., 2004).

In light of this, mitochondria are considered to be a key factor influencing acquisition of oocyte competence and could therefore be a site for the expression of valuable markers that reflect oocyte quality. Any insult that disrupt mitochondrial replication or functioning might impair oocyte competence.

\section{STRESS-INDUCED ALTERATIONS IN OOCYTE DEVELOPMENTAL COMPETENCE}

Regulation of mitochondrial activity in the oocyte is affected by various maternal and environmental factors. Studies have provided evidence that stressors, such as maternal nutrition (Van Hoeck et al., 2013), maternal age (Takeo et al., 2013), environmental contaminants (Kalo et al., 2015), food-origin toxins, inflammatory disease, and thermal stress (Roth, 2017), deleteriously affect the oocyte. The oocyte achieves its developmental competence through the lengthy process of folliculogenesis; therefore, exposing the animal to one of these stressors can potentially lead to reduced competence of the follicle-enclosed oocyte, including maturation, fertilization, and subsequent developmental competence (Roth, 2014). Whereas the intracellular and molecular disruptive mechanism seems to be multifactorial in nature, the oocyte mitochondria are a pivotal target for various stressors. In this section we discuss the effects of 2 main stressors - environmental heat stress and endocrine-disrupting compounds (EDC) - on the oocyte.

\section{Effect of Heat Stress on the Oocyte}

Oocytes harvested from cows during the summer exhibit a lower ability to be fertilized and develop to the blastocyst stage than those harvested during the winter (Gendelman et al., 2010; Figure 1). Moreover, a period of at least 2 to 3 estrous cycles is required for the appearance of developmentally competent oocytes, suggesting a carryover effect from the oocyte to the developing embryo (Roth et al., 2001; Torres-Júnior et al., 2008). The mechanism by which heat stress impairs the oocyte involves alterations in both nuclear eventssuch as impairment in the cytoskeletal microtubulin and microfilaments, spindle apparatus perturbations (Ju and Tseng, 2004), and reduced proportion of oocytes progressing to MII (Payton et al., 2004; Roth and Hansen, 2005; for review see Roth, 2015). Heatinduced alterations in the cytoskeleton are also related to impairments in cytoplasmic maturation events, such as cortical granule translocation (Payton et al., 2004) and mitochondrial distribution (Gendelman and Roth, 2012a). Heat stress also disrupts RNA storage in germinal vesicle-stage oocytes and impairs transcription in mature oocytes (Gendelman et al., 2010). Nevertheless, the association between these stress features and mitochondrial function is not clear.

\section{Effect of Heat Stress on the Oocyte Mitochondria}

Reduced oocyte developmental competence during the summer and subsequent fall is strongly associated with seasonal alterations in mitochondrial features. Mitochondrial transport and repositioning in the cell occur along microtubule tracks and through actin filament rearrangement (Zampolla et al., 2011). Oocytes can be classified into 4 different mitochondrial-distribution categories (Stojkovic et al., 2001; Figure 2a): category I oocytes show homogeneous mitochondrial clumps distributed throughout the oocyte cytoplasm, indicating matured oocytes; category II oocytes are characterized by restricted mitochondrial clumps at the periphery of the oocyte; category III oocytes display a small number of mitochondria with peripheral localization; and category IV are defined as nonviable oocytes. Given that cytoskeletal elements are highly sensitive to elevated temperature (Ozawa et al., 2002), season-induced alterations in the cytoskeletal arrangement might explain the differential pattern of mitochondrial distribution between seasons, expressed by a high proportion of category I oocytes (i.e., mature oocytes) in the winter, a low proportion in the summer, and an intermediate proportion in the fall (Gendelman and Roth, 2012a; Figure 2B). In addition, a clear association between mitochondrial distribution and mitochondrial membrane polarity has been documented, with high mitochondrial polarity for category I and low polarity for category III oocytes. With respect to the latter, a low proportion of oocytes with high mitochondrial membrane potential might explain, in part, the reduced fertilization, 
A

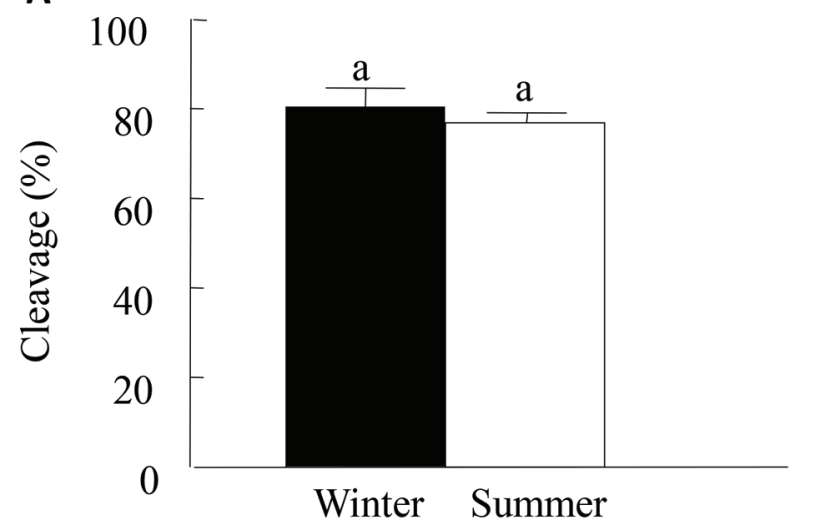

B

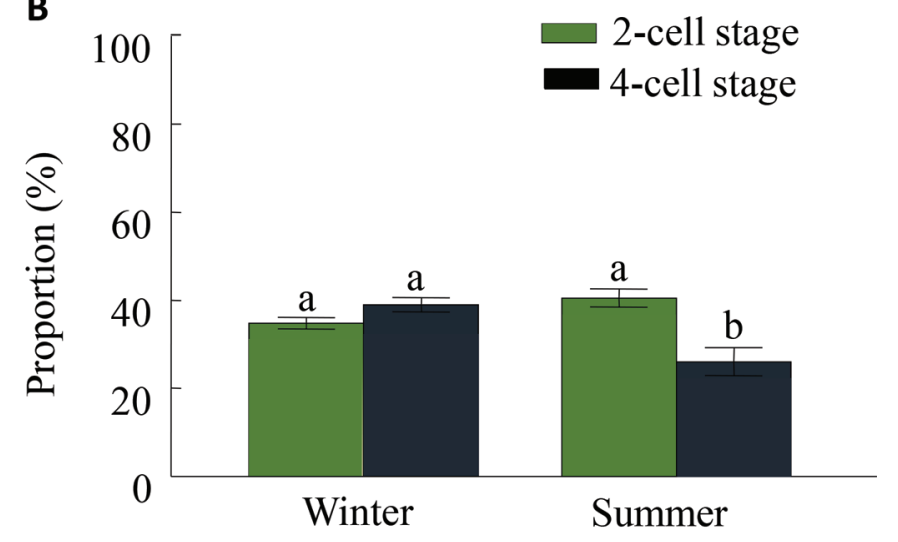

C

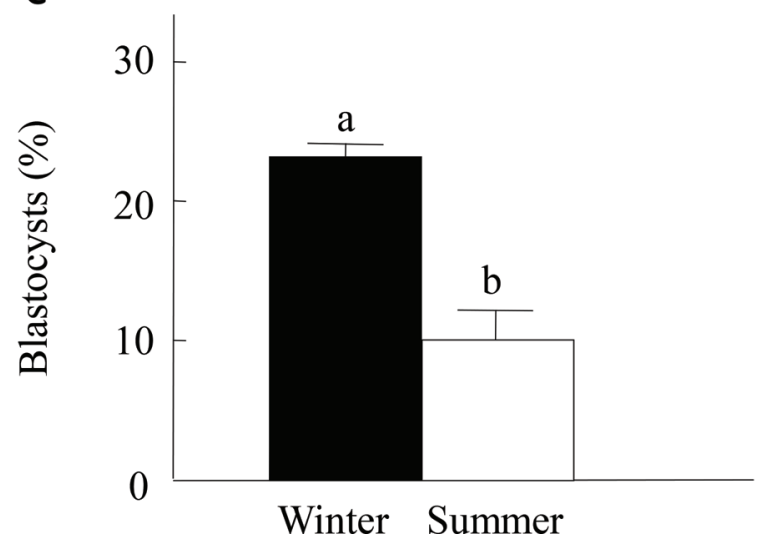

Figure 1. Seasonal effect on oocyte developmental competence. The proportion of oocytes that cleaved ( $42 \mathrm{~h}$ postfertilization) did not differ between seasons (A); however, the proportion of 4-cell stage embryos was higher for oocytes collected during the winter relative to the summer (B). The proportion of embryos that developed to blastocysts 7 to $8 \mathrm{~d}$ postinsemination was higher during the winter (C). Data are presented as means \pm SEM; different letters $(\mathrm{a}, \mathrm{b})$ indicate seasonal effect within embryonic stages $(P<0.05)$. Adapted from Gendelman et al. (2010). Color version available online.

expressed by cleavage rate, after exposure to thermal stress (Roth and Hansen, 2005; Kalo and Roth, 2011). The proportion of oocytes with high polarity was high- er in the winter, intermediate in the fall, and lowest in the summer (Gendelman and Roth, 2012a; Figure $3)$. In support, in vitro exposure of germinal vesicle stage and maturing oocytes to heat shock reduces oocyte mitochondrial activity and membrane potential (Soto and Smith, 2009; Paula-Lopes et al., 2012). As the maternal mitochondria stored in the oocyte are the primary energy source for further embryonic growth, these alterations might explain the delayed embryonic divisions to 2- and 4-cell stages and the reduced proportion of blastocysts developed from oocytes collected during the hot season (Gendelman and Roth, 2012b). Nevertheless, other studies reported that the proportion of cleavage rate did not differ between the summer and winter (Torres-Júnior et al., 2008; Gendelman et al., 2010; Ferreira et al., 2011).

A reduced amount of mtDNA, below the threshold, is proposed to be involved in reduced developmental competence during the summer. However, an examination of mtDNA copy number in mature bovine oocytes did not reveal any differences between seasons (Gendelman and Roth, 2012a); the mtDNA copy number ranged between 400,000 and 800,000 per oocyte, a normal range for mature bovine oocytes. On the other hand, a reduced number of copies mtDNA was associated with reduced blastocyst formation and increased expression of genes related to apoptosis in developing blastocysts (Ferreira et al., 2011). In another study, mtDNA copies were higher by 8 fold in oocytes collected from repeatbreeder cows during the winter relative to those collected during the summer (Ferreira et al., 2016). Although not clear, the expression of nuclear-encoded transcripts related to mtDNA transcription and replication (e.g., NRF1, POLG, POLG2, PPARGC1A, and TFAM) was higher during the summer and inversely correlated with mtDNA content (Ferreira et al., 2016). Taken together, a reduced number of copies mtDNA might explain in part the reduced blastocyst formation during the summer relative to the winter.

Gendelman and Roth (2012a) reported seasoninduced alterations in the expression of genes associated with mitochondrial function; these included both nuclear (SDHD and ATP5B) and mitochondrial (ND2, $C Y T B, C O X I I)$ genes encoding polypeptide subunits involved in constructing the mitochondrial enzyme complexes. Given the important role of each of the mitochondrial electron transport chain complexes, alterations in 1 or more of these components are expected to impair the mitochondrial electron transport chain and cause a decline in ATP levels. The NADH dehydrogenase subunit 2 (ND2) is part of complex I in the mitochondrial electron transport chain that is involved in proton translocation across the inner mitochondrial membrane. Succinate dehydrogenase subunit 
$\mathrm{D}$ (SDHD) is 1 of the 2 transmembrane subunits of complex II. Mitochondrial cytochrome $b$ (CYTB) is a subunit of complex III, which consists of a mitochondrion-encoded gene and 10 nuclear gene products. Cytochrome c oxidase subunit II (COXII) is part of complex IV and transfers electrons from cytochrome c to catalytic subunit 1 . Gene $A T P 5 B$ encodes a subunit of mitochondrial ATP synthase (complex V) and is a subunit of complex F1. Nevertheless, a seasonal effect on the oocyte mitochondrial respiratory chain has not yet been documented for ATP production.

\section{Effect of Endocrine-Disrupting Compounds on the Oocyte}

Environmental toxicants include a variety of widespread man-made chemicals. Some of these have been classified as EDC, as they can interfere with normal endocrine functions (Rhind et al., 2010), such as those in the male and female reproductive systems (Martino-Andrade and Chahoud, 2010). Whereas multiple chemicals have been classified as EDC, in this section we discuss the effects of phthalates on oocyte developmental competence and mitochondrial function. Other EDC, such as polychlorinated biphenyl (PCB), are mentioned as well.

Phthalates are plasticizers used in a variety of industrial plastics applications. They are widely distributed in the air, soil, and water and can easily penetrate an organism's body. For instance, di(2-ethylhexyl) phthalate (DEHP), a commonly used plasticizer, is the most potent toxicant among phthalates and considered a reproductive toxicant for both humans and animals (Kavlock et al., 2002). Oral administration of DEHP to female rats impairs the estrous cycle and inhibits ovulation in association with alterations in estradiol, progesterone, FSH, and LH concentrations (Hirosawa et al., 2006). Exposure of adult mice to DEHP decreases the number of primordial follicles and increases the number of primary ones (Hannon et al., 2014). In vitro exposure of newborn mouse ovaries to DEHP reduces the number of primordial follicles and increases

A
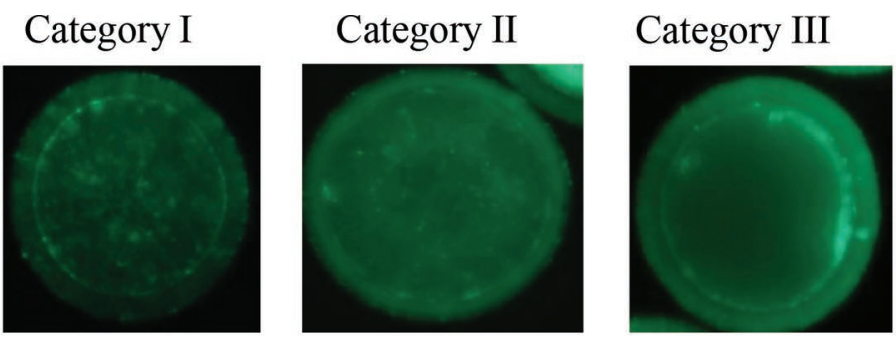

\section{Category IV}
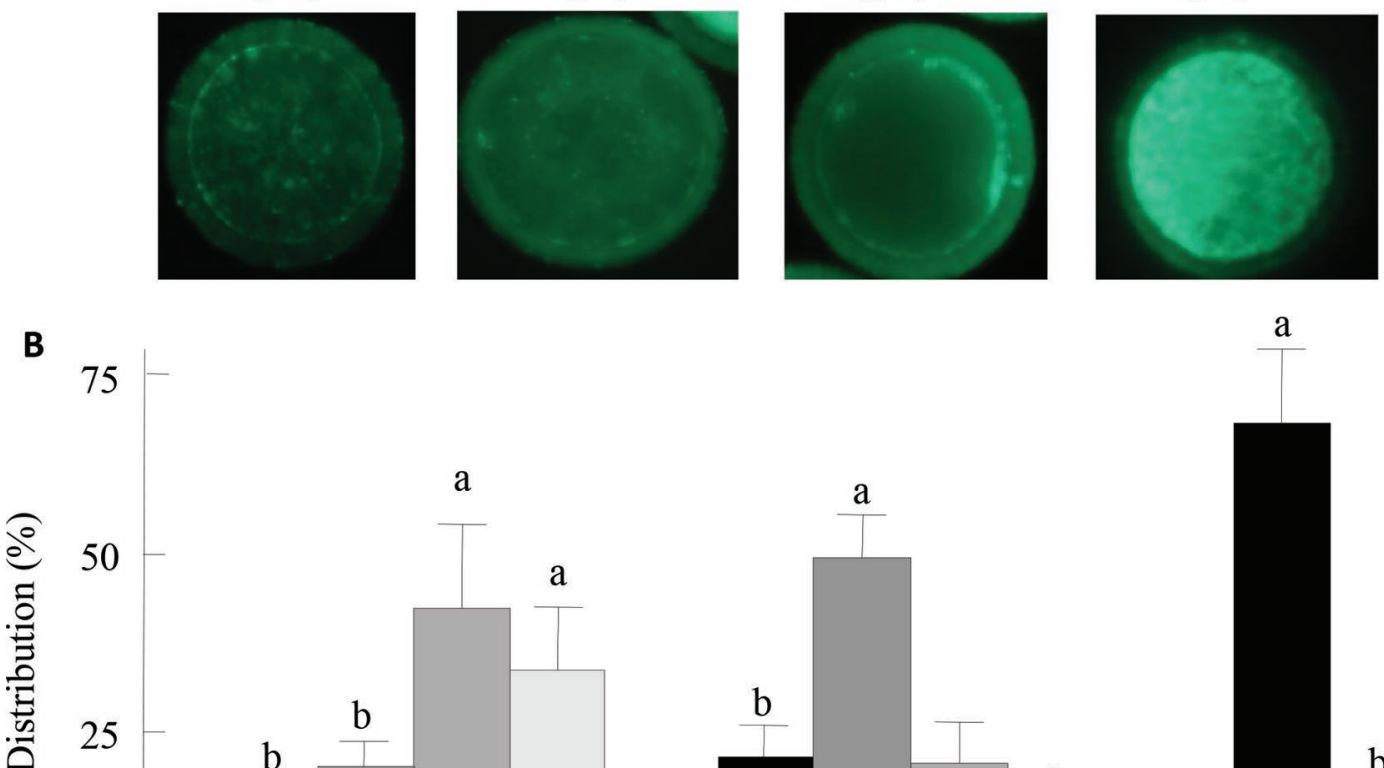

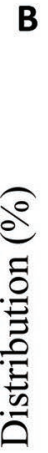

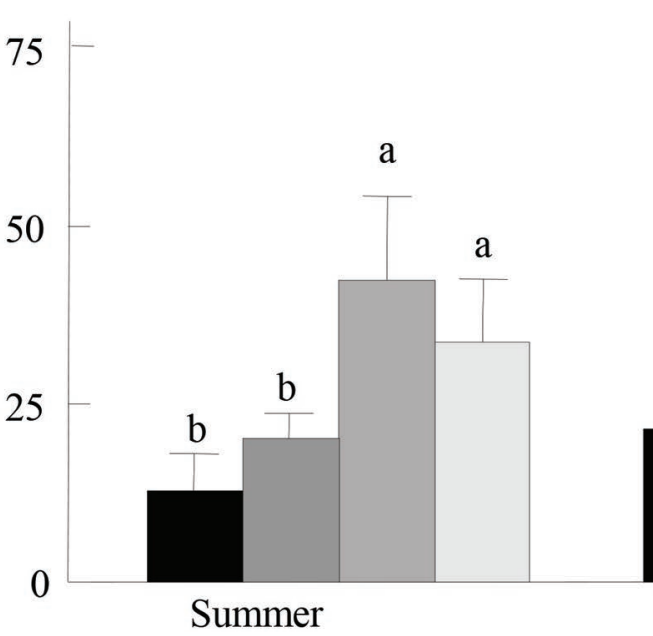

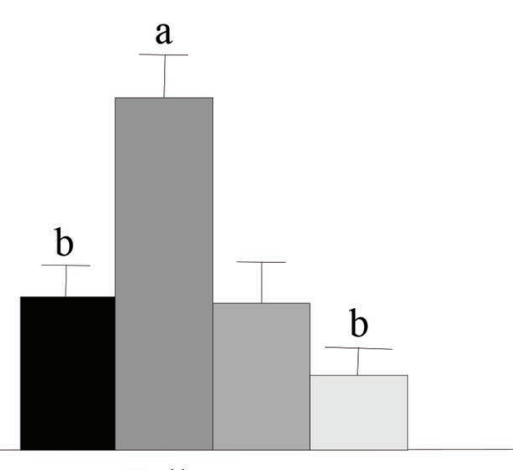

Fall

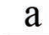

a

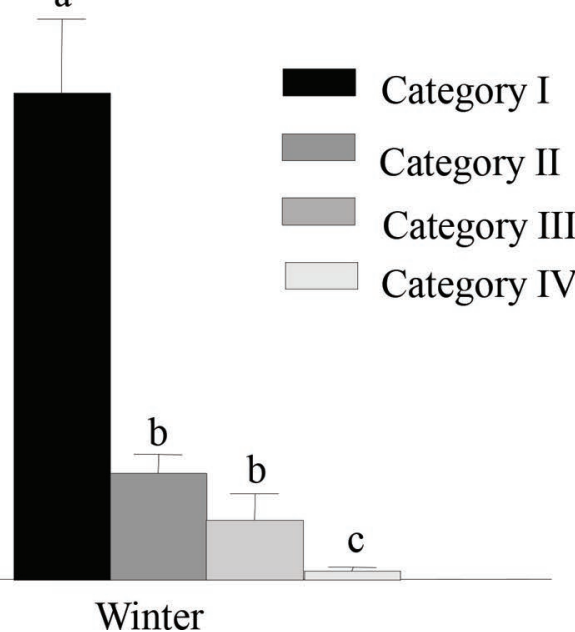

Figure 2. Seasonal effect on oocyte mitochondrial distribution. Oocytes collected during the summer, fall, and winter were stained with MitoTracker (Life Technologies, Carlsbad, CA) green dye at the end of in vitro maturation. (A) Mitochondrial distribution was categorized into

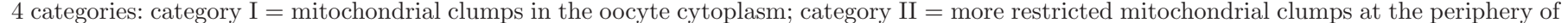

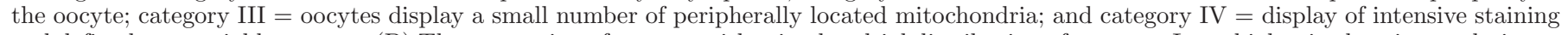
and defined as nonviable oocytes. (B) The proportion of oocytes with mitochondrial distribution of category I was higher in the winter relative to

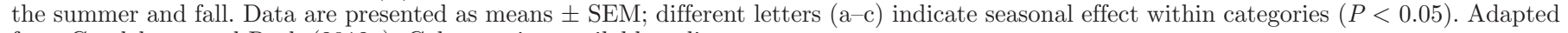
from Gendelman and Roth (2012a). Color version available online. 
A

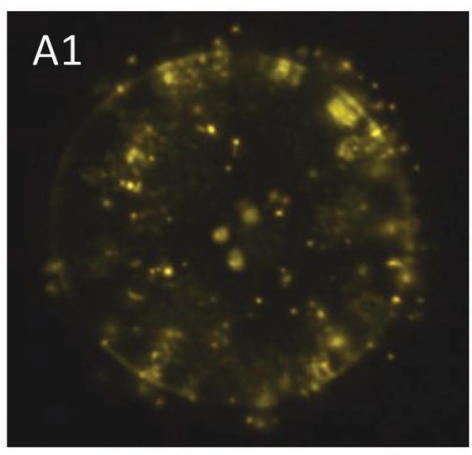

B
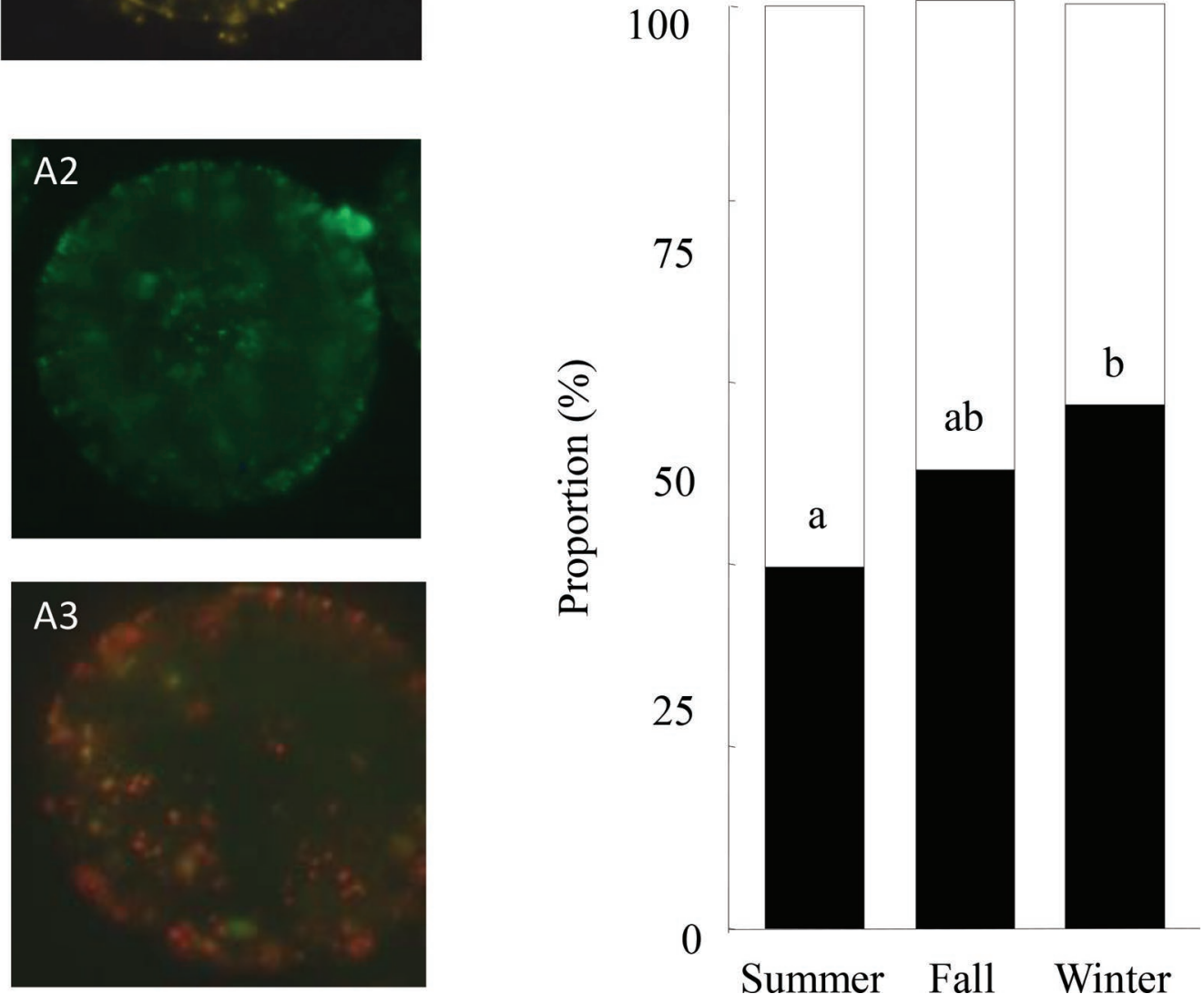

Figure 3. Seasonal variations in oocyte mitochondrial polarization. Bovine oocyte collected during the summer, fall, and winter were stained with JC-1 (Biovision, Milpitas, CA) dye. Presented are representative oocytes with a high mitochondrial membrane potential ( $\Psi \Delta \mathrm{m} ; \mathrm{A} 1)$, low $\Psi \Delta \mathrm{m}$ (A2), and merged staining (A3). The cutoff between high and low $\Psi \Delta \mathrm{m}$ was based on the calculated red-to-green ratio, whereby a value higher than 1 was considered indicative of relatively high $\Psi \Delta \mathrm{m}$ and a value lower than 1 indicated relatively low $\Psi \Delta \mathrm{m}$. The proportion of mitochondria with high $\Psi \Delta \mathrm{m}$ was higher in the winter relative to that in the summer and fall (B). Data are presented as means \pm SEM; different letters $(\mathrm{a}, \mathrm{b})$ indicate seasonal effect $(P<0.05)$. Adapted from Gendelman and Roth $(2012 \mathrm{a})$. Color version available online.

the number of nested germ cells (Zhang et al., 2014). In utero exposure of female rats to high levels of DEHP during gestation increases the number of tertiary follicles undergoing atresia in the offspring (Grande et al., 2007). In domestic animals, DEHP has been found in bovine (Krejč́ková and Jarošová, 2013), ewe (Rhind et al., 2005), and swine (Ljungvall et al., 2004) tissues. Being lipophilic compounds, phthalates are transferred and accumulated in the adipose tissue, and therefore can potentially be released into the circulation during periods of high fat metabolism, such as postpartum or in early lactation (Rhind, 2005). The DEHP is rapidly hydrolyzed by lipases in the gut, liver, and blood into mono(2-ethylhexyl) phthalate (MEHP). Studies in other cell lines have found the mitochondria to be a main target site for phthalates (Rosado-Berrios et al., 2011; Yang et al., 2012). Nevertheless, the effect of DEHP and its metabolites on the oocyte is less known. 


\section{Effect of Phthalates on the Oocyte}

In vitro studies in bovines indicate that both DEHP and its metabolite MEHP have a negative effect on oocyte maturation and developmental competence (Anas et al., 2003; Beker van Woudenberg et al., 2012; Grossman et al., 2012). Exposing oocytes to MEHP during maturation decreased both cleavage and blastocyst-formation rate (Grossman et al., 2012; Figure 4). This was associated with negative effects of MEHP on meiotic progression, manifested by a higher proportion of oocytes that did not progress to the MII stage and complete meiosis. A decreased proportion of MII-stage oocytes was also recorded when bovine cumulus oocyte complexes were exposed to $10,25,50$, and $75 \mu M$ MEHP or higher (Kessler et al., 2012); no meiotic progression was found after exposing denuded oocytes to 50,75 , or $100 \mu M$ MEHP for $24 \mathrm{~h}$. A higher proportion of telophase I-stage oocytes was found in the MEHPtreated group, suggesting a delay in meiotic progress (Hannon and Flaws, 2015).

\section{Effect of Phthalates on the Oocyte Mitochondria}

The MEHP not only affects meiotic progress but also induces changes in cortical granule migration, endoplasmic reticulum reorganization and mitochondrial reorganization (Kalo and Roth, 2015), all of which depend on cytoskeleton-element arrangement. Phthalates were reported to act on the actin cytoskeleton in Pyla rat osteoblasts (Marchetti et al., 2002), and DEHP altered the expression of cytoskeleton-related genes in Syrian hamster embryo cells, in particular upregulating genes involved in actin regulation (Landkocz et al., 2011). Similarly, Aroclor 1254, a mixture of PCB, altered mitochondrial relocation in porcine oocytes (Brevini et al., 2004). Aroclor 1254 also inhibited cortical granule redistribution in bovine oocytes (Pocar et al., 2001) and slowed the rate of spontaneous cortical granule exocytosis in mice (Abbott and Ducibella, 2001). The MEHP reduces the proportion of MII-stage oocytes expressing category I mitochondrial distribution relative to controls (59 vs. 88\%, respectively; Figure 5A; Kalo and Roth, 2015). In light of these findings, it was suggested that MEHP-induced disruption of organelle reorganization involves alterations in the cytoskeleton.

The effect of MEHP is not limited to mitochondrial reorganization; it also induces alterations in mitochondrial function, such as membrane polarity, expressed by reduced proportion of mitochondria with high membrane potential (Figure 5B) and increased ROS level in MEHP-treated oocytes (Figure 5C; Kalo and Roth, 2015). During oocyte maturation, mitochondrial membrane potential increases due to the intensive increase
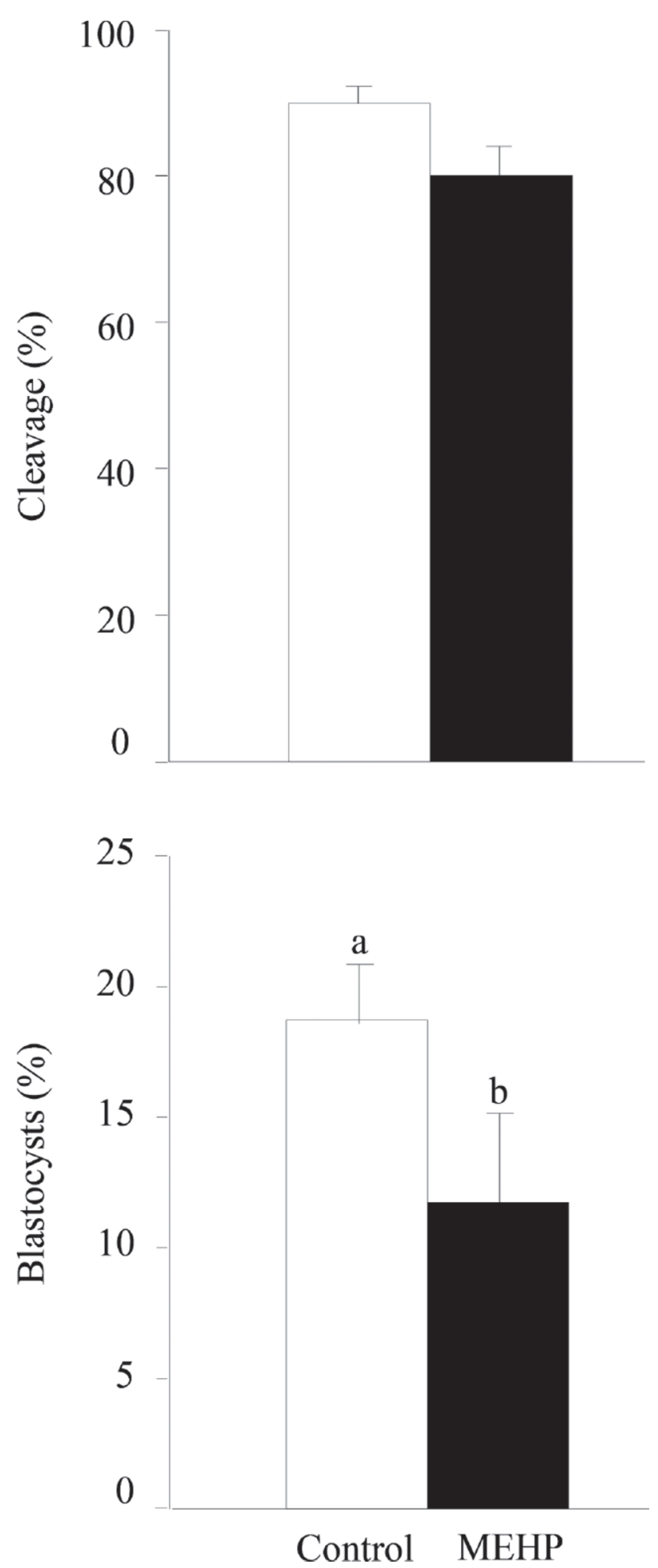

Figure 4. Exposing bovine oocytes to $50 \mu M$ mono(2-ethylhexyl) phthalate (MEHP) reduced oocyte developmental competence. Presented is the proportion of oocytes that cleaved into 2- and 4-cell stage embryos, 42 to $44 \mathrm{~h}$ postfertilization (A) and the proportion of embryos that developed to blastocysts on d 7 to 8 postfertilization (B). Data are presented as means \pm SEM; different letters (a,b) indicate treatment effect within embryonic stages $(P<0.05)$. Adapted from Grossman et al. (2012). 
A

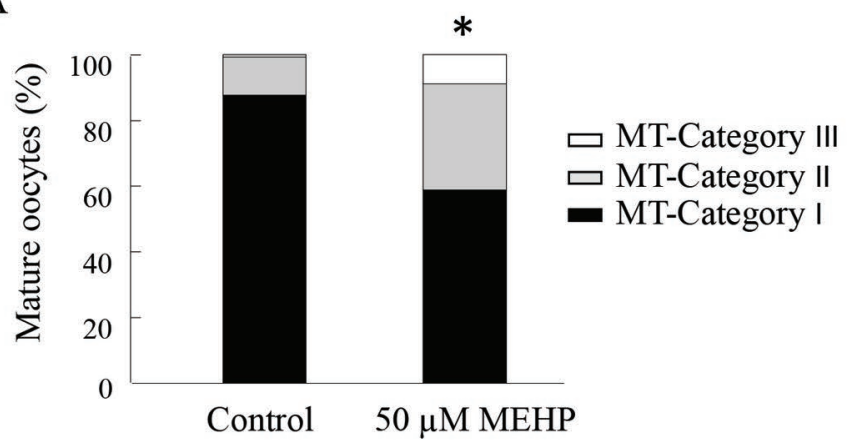

$\mathrm{C}$

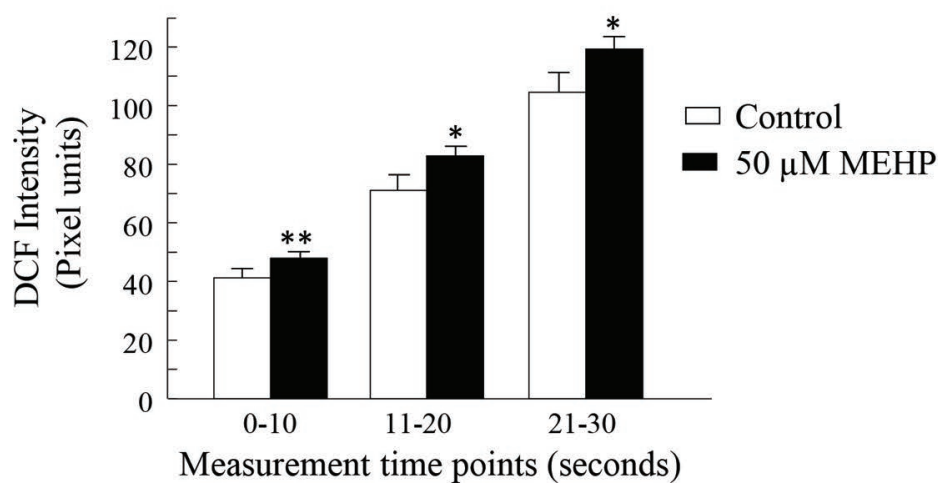

B

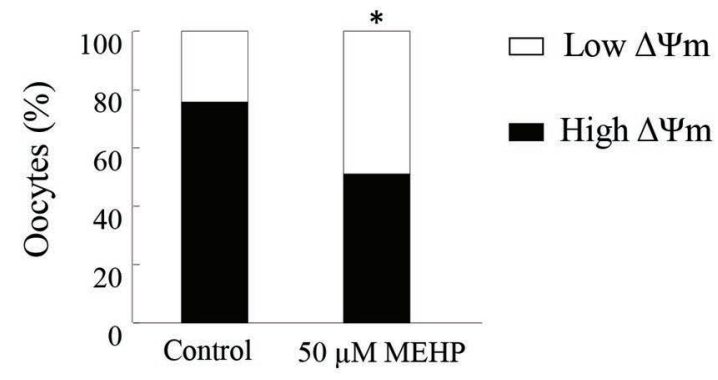

D

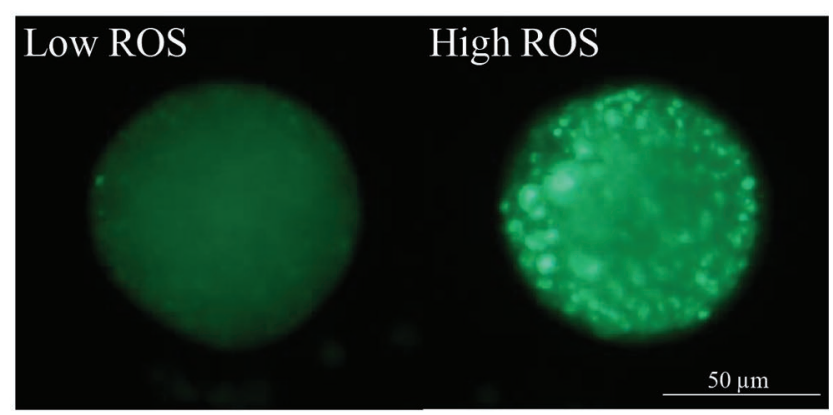

Figure 5. Effect of mono(2-ethylhexyl) phthalate (MEHP) on mitochondrial features. Oocytes were cultured for 22 h without (control) or with $50 \mu M$ MEHP. Presented are the proportion of each category of mitochondrial distribution (I-V) in metaphase II-stage oocytes (A); proportion of oocytes with high- and low-polarized mitochondrial membranes. The cutoff between high- and low-polarized mitochondria was based on the calculated red-to-green ratio, whereby a value higher than 1 was considered indicative of relatively high-polarized mitochondria and a value lower than 1 indicated relatively low-polarized mitochondria (B). Reactive oxygen species (ROS) level expressed by fluorescence intensity in live oocytes; $2^{\prime}, 7^{\prime}$-dichlorofluorescein fluorescence intensity, measured 0 to 10,11 to 20 , and 21 to $30 \mathrm{~s}$ postoocyte maturation. Data are presented as means $\pm \mathrm{SEM} ;{ }^{*} P<0.05$ and ${ }^{* *} P<0.07$ within each time point. Adapted from Kalo and Roth (2015). Color version available online.

in oxidative metabolism required for subsequent embryonic development following fertilization (Van Blerkom et al., 2002; Van Blerkom and Davis, 2007). Therefore, impairment in mitochondrial polarization upon exposure of bovine oocytes to MEHP might explain, in part, the reduced developmental competence of the oocyte (Ambruosi et al., 2011; Grossman et al., 2012).

The MEHP has also been found to induce oxidative stress via elevation in ROS levels in 2-cell stage mouse embryos (Chu et al., 2013a), mouse antral follicles (Wang et al., 2012), and rat germ cells (Kasahara et al., 2002). Nevertheless, it is not clear whether elevation in ROS production is a result of depolarization of the mitochondrial membrane or causes mitochondrial dysfunction in and of itself. Mitochondrial oxidative phosphorylation involves multiple enzymatic complexes and is composed of subunits encoded by both nuclear and mitochondrial genomes (Thundathil et al., 2005). Thus, any mismatch in nuclear or mitochondrial gene expression, or both, might impair electron transport chain activity and thus ROS generation. Kalo and
Roth (2015) reported MEHP-induced alterations in the expressions of both nuclear $(C Y C 1, A T P 5 B)$ and mitochondrial (MT-CO1) genes. Gene CYC1 encodes a subunit of the cytochrome bc1 complex, the third complex in the electron transport chain; $M T-C O 1$ encodes 1 of the 3 subunits forming the catalytic core of cytochrome c oxidase, the last complex of the electron transport chain. In addition, the transcript level of $A T P 5 B$ was higher in MEHP-treated than control oocytes; ATP $5 B$ encodes a subunit of F1 - part of ATP synthase (complex V), the soluble catalytic core. Given that transcription in the oocyte ceases abruptly during maturation (Tomek et al., 2002), the increased ATP5B level in MEHP-treated oocytes could be explained by phthalate's effect on the polyadenylation mechanism and alteration of poly (A) tail length. In support of this, Pocar et al. (2001) reported an effect of PCB on the degree of polyadenylation of specific genes expressed during in vitro maturation of bovine oocytes.

Another mechanism associated with mitochondrial polarity and ROS levels is apoptosis. The MEHP in- 
creased the proportion of TUNEL-positive oocytes (Kalo and Roth, 2015). Accordingly, MEHP altered the expression of $A S A H 1$, an apoptosis-related gene, in mature oocytes and 2-cell-stage embryos (Grossman et al., 2012). A similar effect on the apoptosisassociated genes Bcl2 and Bax was reported for mouse antral follicles (Wang et al., 2012). Phthalates have also been shown to increase DNA fragmentation in equine cumulus cells (Ambruosi et al., 2011) and to induce apoptosis in various cell lines (Chu et al., 2013b; Yang et al., 2015).

\section{STRATEGIES TO IMPROVE OOCYTE MITOCHONDRIAL FUNCTION AND COMPETENCE}

Accumulating evidence suggests that oocyte mitochondria are a pivotal target for various stressors, and that stress-induced alterations in mitochondrial functioning lead to reduced developmental competence of the oocyte and embryo. In light of this understanding, various approaches have been suggested to improve mitochondrial function and thus, oocyte competence.

Treatment with coenzyme Q10 (CoQ10), a ubiquitous free radical scavenger and a key component of the mitochondrial respiratory chain for ATP production has been suggested. Maturation of oocytes with $50 \mu M$ CoQ10 in the fall induced changes in mitochondrial distribution within the oocytes and increased the proportion of polarized mitochondria. Moreover, incorporation of CoQ10 into the oocytes induced changes in gene transcription in association with an enhanced proportion of embryos developing to the blastocyst stage (Gendelman and Roth, 2012a). A similar approach has been used for elderly woman and mice (Ben-Meir et al., 2015). Oocytes aspirated from elderly women were characterized by mitochondrial dysfunction, decreased oxidative phosphorylation, reduced ATP level, and lower expression of Pdss2 and Coq6, encoding the enzymes responsible for CoQ production. This reduction could be reversed by administration with mitochondrial nutrients. Dietary supplementation with CoQ10 may increase mitochondrial activity in compromised oocytes (Bentov et al., 2010).

The balance between intracellular antioxidants (catalase, superoxide dismutase, glutathione) and mitochondrial ROS production might determine the oocyte's fate. Elevated body temperature increases intracellular ROS in bovine oocytes (Nabenishi et al., 2012) and decreases glutathione concentration in mouse oocytes and zygotes (Matsuzuka et al., 2005a). Exposing zygotes to heat shock, either directly or through maternal hyperthermia, resulted in reduced levels of cytosolic glutathione in association with early embryonic loss (Ozawa et al., 2002). Thus, improving the antioxidant capacity and manipulating the oxidation status of the oocyte are suggested as potential strategies to overcome the adverse effects of heat stress. Matsuzuka et al. (2005b) showed that administration of melatonin, another potent ROS scavenger, to heat-stressed mice alleviates hyperthermia-induced early embryonic death. Similarly, treatment of dairy cows with melatonin implants before calving improved their reproductive performance in the summer, as it reduced days open and the number of AI per pregnancy (Garcia-Ispierto et al., 2013). Using a mouse model, Roth et al. (2008) showed that in vivo administration of the antioxidant epigallocatechin gallate (EGCG), the most abundant flavonoid component of green tea, moderates some of the deleterious effects of maternal hyperthermia. Pretreatment of the mother with EGCG (100 mg/kg of BW) increased the proportion of early cleaved embryos and formed blastocysts. Moreover, EGCG administration further reduced the apoptotic status of preimplantation embryos, most likely as a result of its antioxidative or antiapoptotic activities, or both. Similarly, exposing mice to restraint stress, when the oocytes were in the prematuration stage, impaired their developmental competence by inducing oxidative stress; maternal EGCG injection overcame these effects (Lian et al., 2013).

Studies in humans and animals have shown that ooplasm or mitochondrion transfer can improve compromised oocyte mitochondrial activity. Cytoplasmic transfer during intracytoplasmic sperm injection procedure improves embryo formation, implantation, and rate of live births (Barritt et al., 2001). Treatment of bovine oocytes with ethidium bromide depleted their mtDNA content and reduced further embryonic development. Cytoplasmic transfer to these treated oocytes reversed the damage to their developmental competence (Chiaratti et al., 2011). Treatment of poor-quality bovine oocytes with mitochondria obtained from the animal's own granulosa cells resulted in dramatic improvements in oocyte quality as well as in blastocyst formation rate (Hua et al., 2007), suggesting that mitochondrial homoplasmy is preferable. In support of this, microinjection of mitochondria obtained from the same breed improved embryo quality during preimplantation development (Hua et al., 2007). Supplementation of mitochondria, isolated from MII-stage oocytes, to mtDNA-deficient pig oocytes at fertilization promoted mtDNA replication before embryonic genome activation and increased blastocyst development (Cagnone et al., 2016). This approach highlights the pivotal role of the mitochondria in oocyte developmental competence and that transferring of mitochondria to oocytes can improve oocyte developmental competence. It should be noted, however, that the cell type used as source of mitochondria (i.e., somatic cells, own granulosa cells, 


\section{Environmental}

Stressors

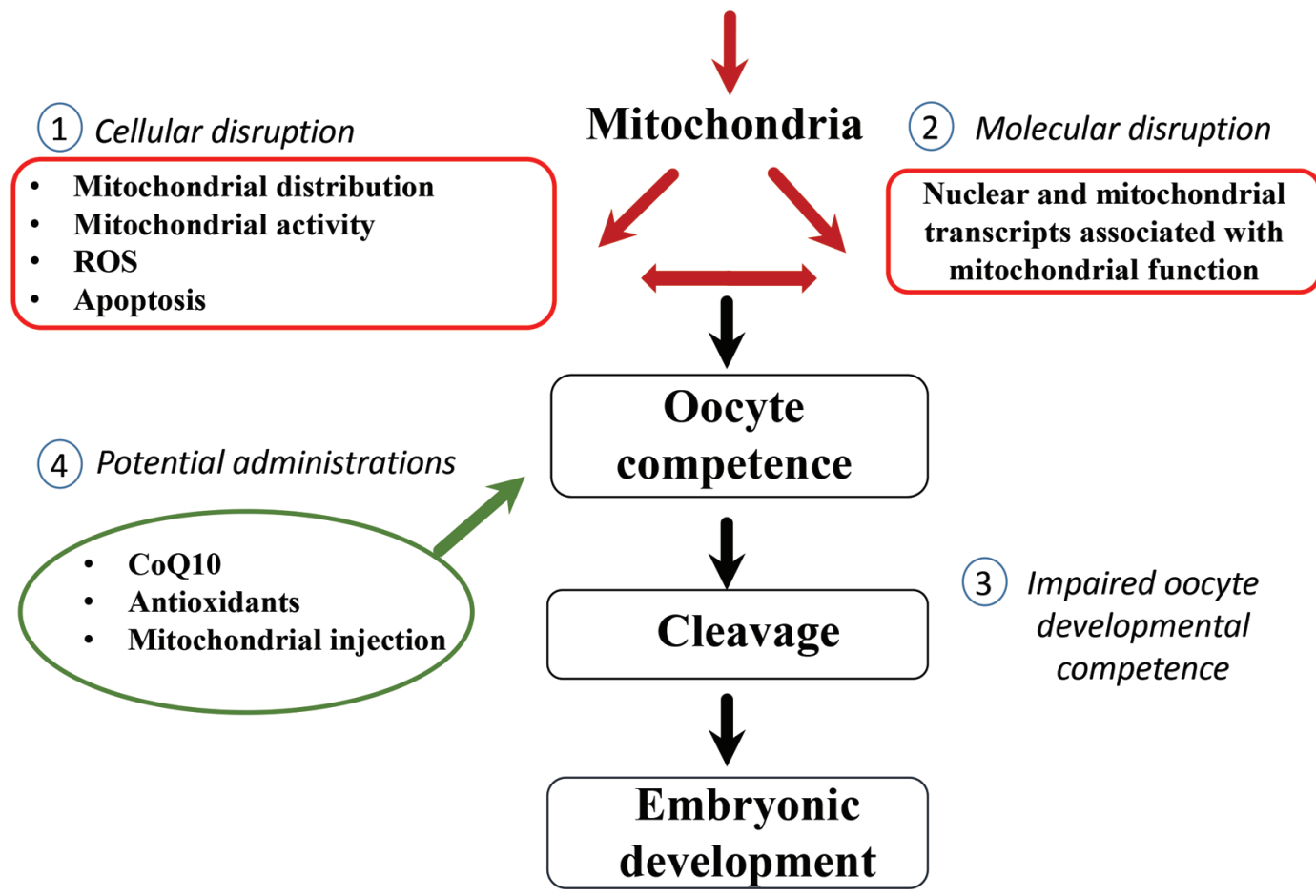

Figure 6. Diagram illustrating the effects of environmental stressors on the oocyte mitochondria. Stress induces cellular (1) and molecular (2) alterations in the oocyte, which in turn might reduce oocyte developmental competence (3). Administration of oocytes with mitochondrial nutrients [coenzyme Q10 (CoQ10)], antioxidants [epigallocatechin gallate (EGCG), melatonin], or injection of mitochondria have been shown to alleviate these effects (4) and to improve oocyte developmental competence. ROS $=$ reactive oxygen species. Color version available online.

germ line cells) is critical to the safety of the offspring (for review see Chappel, 2013).

\section{SUMMARY}

The current review highlights the effects of environmental stressors (i.e., thermal stress, EDC exposure) on oocyte developmental competence (Figure 6). Despite the diversity in the stressors' modes of action, the mitochondrial response is proposed to be a pivotal cause for reduced oocyte quality under stress. New approaches to maintaining or improving oocyte mitochondrial function are greatly needed to improve the fertility of both humans and farm animals. Although various antioxidative agents have been used to combat oxidative stress, none has yet been implemented in practice. I believe that nutritional strategies involving the consumption of high-quality food that is free of toxins and enriched with antioxidants can alleviate, to some extent, the effects of stress on fertility. In support of this assumption, Aréchiga et al. (1998) reported that feeding a $\beta$-carotene supplement for at least $90 \mathrm{~d}$ from $\sim 15 \mathrm{~d}$ after calving increases the proportion of pregnant cows at $120 \mathrm{~d}$ postpartum by 14 percentage units, suggesting that long-term, rather than periodic administration, is required.

\section{ACKNOWLEDGMENTS}

The studies were supported by (1) Binational Agricultural Research and Developmental Fund (BARD), project US-3986-07, and (2) The Environment and Health Fund, Jerusalem, Israel.

\section{REFERENCES}

Abbott, A. L., and T. Ducibella. 2001. Calcium and the control of mammalian cortical granuleexocytosis. Front. Biosci. 6:D792-806.

Ambruosi, B., M. F. Uranio, A. M. Sardanelli, P. Pocar, N. A. Martino, M. S. Paternoster, F. Amati, and M. E. Dell'Aquila. 2011. In vitro acute exposure to DEHP affects oocyte meiotic maturation, energy and oxidative stress parameters in a large animal model. PLoS One 6:e27452.

Anas, M. K., C. Suzuki, K. Yoshioka, and S. Iwamura. 2003. Effect of mono-(2-ethylhexyl) phthalate on bovine oocyte maturation in vitro. Reprod. Toxicol. 17:305-310. 
Andersson, S. G., O. Karlberg, B. Canback, and C. G. Kurland. 2003. On the origin of mitochondria: A genomics perspective. Philos. Trans. R. Soc. Lond. B Biol. Sci. 358:165-177.

Aréchiga, C. F., C. R. Staples, L. R. McDowell, and P. J. Hansen. 1998. Effects of timed insemination and supplemental beta-carotene on reproduction and milk yield of dairy cows under heat stress. J. Dairy Sci. 81:390-402.

Barritt, J. A., C. A. Brenner, H. E. Malter, and J. Cohen. 2001. Mitochondria in human offspring derived from ooplasmic transplantation. Hum. Reprod. 16:513-516.

Bavister, B. D., and J. M. Squirrell. 2000. Mitochondrial distribution and function in oocytes and early embryos. Hum. Reprod. 15:189-198.

Beker van Woudenberg, A., M. Gröllers-Mulderij, C. Snel, N. Jeurissen, R. Stierum, and A. Wolterbeek. 2012. The bovine oocyte in vitro maturation model: A potential tool for reproductive toxicology screening. Reprod. Toxicol. 34:251-260.

Ben-Meir, A., E. Burstein, A. Borrego-Alvarez, J. Chong, E. Wong, T. Yavorska, T. Naranian, M. Chi, Y. Wang, Y. Bentov, J. Alexis, J. Meriano, H. K. Sung, D. L. Gasser, K. H. Moley, S. Hekimi, R. F. Casper, and A. Jurisicova. 2015. Coenzyme Q10 restores oocyte mitochondrial function and fertility during reproductive aging. Aging Cell 14:887-895.

Bentov, Y., N. Esfandiari, E. Burstein, and R. F. Casper. 2010. The use of mitochondrial nutrients to improve the outcome of infertility treatment in older patients. Fertil. Steril. 93:272-275.

Brevini, T. A., R. Vassena, A. Paffoni, C. Francisci, U. Fascio, and F. Gandolfi. 2004. Exposure of pig oocytes to PCBs during in vitro maturation: effects on developmental com-petence, cytoplasmic remodeling and communications with cumulus cells. Eur. J. Histochem. 48:347-356.

Cagnone, G. L., T. S. Tsai, Y. Makanji, P. Matthews, J. Gould, M. S. Bonkowski, K. D. Elgass, A. S. Wong, L. E. Wu, M. McKenzie, D. A. Sinclair, and J. C. St. John. 2016. Restoration of normal embryogenesis by mitochondrial supplementation in pig oocytes exhibiting mitochondrial DNA deficiency. Sci. Rep. 6:23229.

Cannino, G., C. M. Di Liegro, and A. M. Rinaldi. 2007. Nuclearmitochondrial interaction. Mitochondrion 7:359-366.

Chappel, S. 2013. The role of mitochondria from mature oocyte to viable blastocyst. Obstet. Gynecol. Int. 2013:183024.

Chase, J. W., and I. B. Dawid. 1972. Biogenesis of mitochondria during Xenopus laevis development. Dev. Biol. 27:504-518.

Chiaratti, M. R., C. R. Ferreira, F. Perecin, S. C. Méo, J. R. Sangalli, L. G. Mesquita, J. C. de Carvalho Balieiro, L. C. Smith, J. M. Garcia, and F. V. Meirelles. 2011. Ooplast-mediated developmental rescue of bovine oocytes exposed to ethidium bromide. Reprod. Biomed. Online 22:172-183.

Chu, D. P., S. Tian, L. Qi, C. J. Hao, H. F. Xia, and X. Ma. 2013b. Abnormality of maternal-to-embryonic transition contributes to MEHP-induced mouse 2-cell block. J. Cell. Physiol. 228:753-763.

Chu, D. P., S. Tian, D. G. Sun, C. J. Hao, H. F. Xia, and X. Ma. 2013a. Exposure to mono-n-butyl phthalate disrupts the development of preimplantation embryos. Reprod. Fertil. Dev. 25:1174-1184.

Dumollard, R., M. Duchen, and J. Carroll. 2007. The role of mitochondrial function in the oocyte and embryo. Curr. Top. Dev. Biol. $77: 21-49$.

Ferreira, R. M., H. Ayres, M. R. Chiaratti, M. L. Ferraz, A. B. Araujo, C. A. Rodrigues, Y. F. Watanabe, A. A. Vireque, D. C. Joaquim, L. C. Smith, F. V. Meirelles, and P. S. Baruselli. 2011. The low fertility of repeat-breeder cows during summer heat stress is related to a low oocyte competence to develop into blastocysts. J. Dairy Sci. 94:2383-2392.

Ferreira, R. M., M. R. Chiaratti, C. H. Macabelli, C. A. Rodrigues, M. L. Ferraza, Y. F. Watanabe, L. C. Smith, F. V. Meirelles, and P. S. Baruselli. 2016. The infertility of repeat breeder cows during summer is associated with decreased mitochondrial DNA and increased expression of mitochondrial and apoptotic genes in oocytes. Biol. Reprod. 94:66.

Garcia-Ispierto, I., A. Abdelfatah, and F. Lopez-Gatius. 2013. Melatonin treatment at dry-off improves reproductive performance post- partum in high-producing dairy cows under heat stress conditions. Reprod. Domest. Anim. 48:577-583.

Gendelman, M., A. Aroyo, S. Yavin, and Z. Roth. 2010. Seasonal effects on gene expression, cleavage timing, and developmental competence of bovine preimplantation embryos. Reproduction 140:73-82.

Gendelman, M., and Z. Roth. 2012a. Incorporation of coenzyme Q10 into bovine oocytes improves mitochondrial features and alleviates the effects of summer thermal stress on developmental competence. Biol. Reprod. 87:118.

Gendelman, M., and Z. Roth. 2012b. In vivo vs. in vitro models for studying the effects of elevated temperature on the GV-stage oocyte, subsequent developmental competence and gene expression. Anim. Reprod. Sci. 134:125-134.

Grande, S. W., A. J. Andrade, C. E. Talsness, K. Grote, A. Golombiewski, A. Sterner-Kock, and I. Chahoud. 2007. A dose response study following in utero and lactational exposure to di-(2-ethylhexyl) phthalate (DEHP): Reproductive effects on adult female offspring rats. Toxicology 229:114-122.

Grossman, D. D. Kalo, M. Gendelman, and Z. Roth. 2012. Effect of di-(2-ethylhexyl) phthalate and mono-(2-ethylhexyl) phthalate on in vitro developmental competence of bovine oocytes. Cell Biol. Toxicol. 28:383-396.

Gunter, T. E., D. I. Yule, K. K. Gunter, R. A. Eliseev, and J. D. Salter. 2004. Calcium and mitochondria. FEBS Lett. 567:96-102.

Hannon, P. R., and J. A. Flaws. 2015. The effect of phthalates on the ovary. Front. Endocrinol. (Lausanne) 6:8.

Hannon, P. R., J. Peretz, and J. A. Flaws. 2014. Daily exposure to $\operatorname{Di}(2$ ethylhexyl $)$ phthalate alters estrous cyclicity and accelerates primordial follicle recruitment potentially via dysregulation of the phosphatidylinositol 3-kinase signaling pathway in adult mice. Biol. Reprod. 90:136.

Hirosawa, N., K. Yano, Y. Suzuki, and Y. Sakamoto. 2006. Endocrine disrupting effect of di-(2-ethylhexyl)phthalate on female rats and proteome analyses of their pituitaries. Proteomics 6:958-971.

Hua, S., Y. Zhang, X. C. Li, L. B. Ma, J. W. Cao, J. P. Dai, and R. Li. 2007. Effects of granulosa cell mitochondria transfer on the early development of bovine embryos in vitro. Cloning Stem Cells 9:237-246.

Jansen, R. P. S. 2000. Origin and persistence of the mitochondrial genome. Hum. Reprod. 15:1-10.

Jones, A., J. Van Blerkom, P. Davis, and A. Toledo. 2004. Cryopreservation of metaphase II human oocytes effects mitochondrial membrane potential: implications for developmental competence. Hum. Reprod. 19:1861-1866.

Ju, J. C., and J. K. Tseng. 2004. Nuclear and cytoskeletal alterations of in vitro matured porcine oocytes under hyperthermia. Mol. Reprod. Dev. 68:125-133.

Kalo, D., R. Hadas, O. Furman, J. Ben-Ari, Y. Maor, D. G. Patterson, C. Tomey, and Z. Roth. 2015. Carryover effects of acute DEHP exposure on ovarian function and oocyte developmental competence in lactating cows. PLoS One 10:e0130896.

Kalo, D., and Z. Roth. 2011. Involvement of the sphingolipid ceramide in heat shock-induced apoptosis of bovine oocytes. Reprod. Fertil. Dev. 23:876-888.

Kalo, D., and Z. Roth. 2015. Effects of mono(2-ethylhexyl)phthalate on cytoplasmic maturation of oocytes-the bovine model. Reprod. Toxicol. 53:141-151.

Kasahara, E., E. F. Sato, M. Miyoshi, R. Konaka, K. Hiramoto, J. Sasaki, M. Tokuda, Y. Nakano, and M. Inoue. 2002. Role of oxidative stress in germ cell apoptosis induced by di(2-ethylhexyl)phthalate. Biochem. J. 365:849-856.

Kavlock, R., K. Boekelheide, R. Chapin, M. Cunningham, E. Faustman, P. Foster, M. Golub, R. Henderson, I. Hinberg, R. Little, J. Seed, K. Shea, S. Tabacova, R. Tyl, P. Williams, and T. Zacharewski. 2002. NTP Center for the Evaluation of Risks to Human Reproduction: Phthalates expert panel report on the reproductive and developmental toxicity of di(2-ethylhexyl) phthalate. Reprod. Toxicol. 16:529-653. 
Kessler, W., W. Numtip, W. Völkel, E. Seckin, G. A. Csanády, C. Pütz, D. Klein, H. Fromme, and J. G. Filser. 2012. Kinetics of di(2-ethylhexyl)phthalate (DEHP) and mono(2-ethylhexyl) phthalate in blood and of DEHP metabolites in urine of male volunteers after single ingestion of ring-deuterated DEHP. Toxicol. Appl. Pharmacol. 264:284-291.

Krejč́́ková, M., and A. Jarošová. 2013. Phthalate in cow milk depending on the method of milking. Pages 592-596 in Medelnet [Internet]. Accessed Jan. 17, 2018. http://mnet.mendelu.cz/ mendelnet2013/articles/44_krejcikova_795.pdf.

Landkocz, Y., P. Poupin, F. Atienzar, and P. Vasseur. 2011. Transcriptomic effects of di-(2-ethylhexyl)-phthalate in Syrian hamster embryo cells: An important role of early cytoskeleton disturbances in carcinogenesis? BMC Genomics 12:524.

Lian, H. Y., Y. Gao, G. Z. Jiao, M. J. Sun, X. F. Wu, T. Y. Wang, H. Li, and J. H. Tan. 2013. Antioxidant supplementation overcomes the deleterious effects of maternal restraint stress-induced oxidative stress on mouse oocytes. Reproduction 146:559-568.

Ljungvall, K., B. Tienpont, F. David, U. Magnusson, and K. Törneke. 2004. Kinetics of orally administered di(2-ethylhexyl) phthalate and its metabolite, mono(2-ethylhexyl) phthalate, in male pigs. Arch. Toxicol. 78:384-389.

Marchetti, L., M. G. Sabbieti, M. Menghi, S. Materazzi, M. M. Hurley, and G. Menghi. 2002. Effects of phthalate esters on actin cytoskeleton of Pyla rat osteoblasts. Histol. Histopathol. 17:1061-1066.

Martino-Andrade, A. J., and I. Chahoud. 2010. Reproductive toxicity of phthalate esters. Mol. Nutr. Food Res. 54:148-157.

Matsumoto, L., H. Kasamatsu, L. Piko, and J. Vinograd. 1974. Mitochondrial DNA replication in sea urchin oocytes. J. Cell Biol. 63:146-159.

Matsuzuka, T., M. Ozawa, A. Nakamure, A. Ushitani, M. Hirabayashi, and Y. Kanai. 2005a. Effects of heat stress on the redox status in the oviduct and early embryonic development in mice. J. Reprod. Dev. 51:281-287.

Matsuzuka, T., N. Sakamoto, M. Ozawa, A. Ushitani, M. Hirabayashi, and Y. Kanai. 2005b. Alleviation of maternal hyperthermia-induced early embryonic death by administration of melatonin to mice. J. Pineal Res. 39:217-223.

May-Panloup, P., M. F. Chretien, C. Jacques, C. Vasseur, Y. Malthiery, and P. Reynier. 2005. Low oocyte mitochondrial DNA content in ovarian insufficiency. Hum. Reprod. 20:593-597.

Michaels, G. S., W. W. Hauswirth, and P. J. Laipis. 1982. Mitochondrial DNA copy number in bovine oocytes and somatic cells. Dev. Biol. 94:246-251.

Motta, P. M., S. A. Nottola, S. Makabe, and R. Heyn. 2000. Mitochondrial morphology in human fetal and adult female germ cells. Hum Reprod. 15:129-147.

Nabenishi, H., S. Takagi, H. Kamata, T. Nishimoto, T. Morita, K. Ashizawa, and Y. Tsuzuki. 2012. The role of mitochondrial transition pores on bovine oocyte competence after heat stress, as determined by effects of cyclosporin A. Mol. Reprod. Dev. 79:31-40.

Ozawa, M., M. Hirabayashi, and Y. Kanai. 2002. Developmental competence and oxidative state of mouse zygotes heat-stressed maternally or in vitro. Reproduction 124:683-689.

Paula-Lopes, F. F., R. S. Lima, P. H. B. Risolia, J. Ispada, M. E. O. A. Assumpcao, and J. A. Visintin. 2012. Heat stress induced alteration in bovine oocytes: functional and cellular aspects. Anim. Reprod. 9:395-403.

Payton, R. R., R. Romar, P. Coy, A. M. Saxton, J. L. Lawrence, and J. L. Edwards. 2004. Susceptibility of bovine germinal vesicel-stage oocytes from antral follicles to direct effects of heat stress in vitro. Biol. Reprod. 71:1303-1308.

Pikó, L., and K. D. Taylor. 1987. Amounts of mitochondrial DNA and abundance of some mitochondrial gene transcripts in early mouse embryos. Dev. Biol. 123:364-374.

Pocar, P., T. A. Brevini, F. Perazzoli, F. Cillo, S. Modina, and F, Gandolfi. 2001. Cellular and molecular mechanisms mediating the effects of polychlorinatedbiphenyls on oocyte developmental competence in cattle. Mol. Reprod. Dev. 60:535-541.

Poyton, R. O., and J. E. McEwen. 1996. Crosstalk between nuclear and mitochondrial genomes. Annu. Rev. Biochem. 65:563-607.
Rhind, S. M. 2005. Are endocrine disrupting compounds a threat to farm animal health, welfare and productivity? Reprod. Domest. Anim. 40:282-290.

Rhind, S. M., N. P. Evans, M. Bellingham, R. M. Sharpe, C. Cotinot, B. Mandon-Pepin, B. Loup, K. D. Sinclair, R. G. Lea, P. Pocar, B. Fischer, E. van der Zalm, K. Hart, J. S. Schmidt, M. R. Amezaga, and P. A. Fowler. 2010. Effects of environmental pollutants on the reproduction and welfare of ruminants. Animal 4:1227-1239.

Rhind, S. M., C. E. Kyle, G. Telfer, E. I. Duff, and A. Smith. 2005. Alkyl phenols and diethylhexyl phthalate in tissues of sheep grazing pastures fertilized with sewage sludge or inorganic fertilizer. Environ. Health Perspect. 113:447-453.

Rosado-Berrios, C. A., C. Vélez, and B. Zayas. 2011. Mitochondrial permeability and toxicityof di ethylhexyl and mono ethylhexyl phthalates on TK6 human lymphoblastscells. Toxicol. In Vitro 25:2010-2016.

Roth, Z. 2014. Effects of heat stress on ovarian functions and embryonic development. Pages 193-208 in Reproduction in Domestic Ruminants VIII. J. L., Juengel, A. Miyamoto, L. P. Reynolds, M. F. Smith, and R. Webb, ed. Context Publishing, Packington, Leicestershire, UK.

Roth, Z. 2015. Cellular and molecular mechanisms of heat stress related to bovine ovarian function. J. Anim. Sci. 93:2034-2044.

Roth, Z. 2017. Effect of heat stress on reproduction in dairy cows: Insights into the cellular and molecular responses of the oocyte. Annu. Rev. Anim. Biosci. 5:151-170.

Roth, Z., A. Arav, A. Bor, Y. Zeron, R. Braw-Tal, and D. Wolfenson. 2001. Improvement of quality of oocytes collected in the autumn by enhanced removal of impaired follicles from previously heatstressed cows. Reproduction 122:737-744.

Roth, Z., A. Aroyo, S. Yavin, and A. Arav. 2008. The antioxidant epigallocatechin gallate (EGCG) moderates the deleterious effects of maternal hyperthermia on follicle-enclosed oocytes in mice. Theriogenology 70:887-897.

Roth, Z., and P. J. Hansen. 2005. Disruption of nuclear maturation and rearrangement of cytoskeletal elements in bovine oocytes exposed to heat shock during maturation. Reproduction 129:235-244.

Smith, L. C., and A. A. Alcivar. 1993. Cytoplasmic inheritance and its effects on development and performance. J. Reprod. Fertil. Suppl. 48:31-43.

Soto, P., and L. C. Smith. 2009. BH4 peptide derived from Bcl-xL and Bax-inhibitor peptide suppresses apoptotic mitochondrial changes in heat stressed bovine oocytes. Mol. Reprod. Dev. 76:637-646.

St John, J. C., J. Facucho-Oliveira, Y. Jiang, R. Kelly, and R. Salah. 2010. Mitochondrial DNA transmission, replication and inheritance: a journey from the gamete through the embryo and into offspring and embryonic stem cells. Hum. Reprod. Update 16:488 509

Stojkovic, M., S. A. Machado, P. Stojkovic, V. Zakhartchenko, P. Hutzler, P. B. Goncalves, and E. Wold. 2001. Mitochondrial distribution and adenosine triphosphate content of bovine oocytes before and after in vitro maturation: correlation with morphological criteria and developmental capacity after in vitro fertilization and culture. Biol. Reprod. 64:904-909.

Szabo, S., Y. Tache, and A. Somogyi. 2012. The legacy of Hans Selye and the origins of stress research: A retrospective 75 years after his landmark brief "letter" to the editor of nature. Stress 15:472-478.

Takeo, S., H. Goto, T. Kuwayama, Y. Monji, and H. Iwata. 2013. Effect of maternal age on the ratio of cleavage and mitochondrial DNA copy number in early developmental stage bovine embryos. J. Reprod. Dev. 59:174-179.

Thundathil, J., F. Filion, and L. C. Smith. 2005. Molecular control of mitochondrial functionin preimplantation mouse embryos. Mol. Reprod. Dev. 71:405-413.

Tomek, W., H. Torner, and W. Kanitz. 2002. Comparative analysis of protein synthesis, transcription and cytoplasmic polyadenylation of mRNA during maturation of bovine oocytes in vitro. Reprod. Domest. Anim. 37:86-91.

Torres-Júnior, J. R. de S., M. de F. A. Pires, W. F. de Sa, A. Ferreira, J. H. Viana, L. S. Camargo, A. A. Ramos, I. M. Folhadella, J. Polisseni, C. de Freitas, C. A. Clemente, M. F. de Sa Filho, F. F. 
Paula Lopes, and P. S. Baruselli. 2008. Effect of maternal heatstress on follicular growth and oocyte competence in Bos indicus cattle. Theriogenology 69:155-166.

Tsang, W. Y., and B. D. Lemire. 2002. Mitochondrial genome content is regulated during nematode development. Biochem. Biophys. Res. Commun. 291:8-16.

Van Blerkom, J., and P. Davis. 2007. Mitochondrial signaling and fertilization. Mol. Hum. Reprod. 13:759-770.

Van Blerkom, J., P. Davis, and J. Lee. 1995. ATP content of human oocytes and develop-mental potential and outcome after in vitro fertilization and embryo transfer. Hum. Reprod. 10:415-424.

Van Blerkom, J., P. Davis, V. Mathwig, and S. Alexander. 2002. Domains of high-polarizedand low-polarized mitochondria may occur in mouse and human oocytes and early embryos. Hum. Reprod. $17: 393-406$.

Van Hoeck, V., J. L. Leroy, M. Arias Alvarez, D. Rizos, A. GutierrezAdan, K. Schnorbusch, P. E. Bols, H. J. Leese, and R. G. Sturmey. 2013. Oocyte developmental failure in response to elevated nonesterified fatty acid concentrations: mechanistic insights. Reproduction 145:33-44.

Wang, G., and S. Yan. 1992. Mitochondrial DNA content and mitochondrial gene transcriptional activities in the early development of loach and goldfish. Int. J. Dev. Biol. 36:477-482.

Wang, W., Z. R. Craig, M. S. Basavarajappa, K. S. Hafner, and J. A. Flaws. 2012. Mono-(2-ethylhexyl) phthalate induces oxidative stress and inhibits growth of mouse ovarian antral follicles. Biol. Reprod. 87:152.

Yang, G., W. Zhang, Q. Qin, J. Wang, H. Zheng, W. Xiong, and J. Yuan. 2015. Mono(2-ethylhexyl)phthalate induces apoptosis in p53-silenced L02 cells via activation of both mitochondrial and death receptor pathways. Environ. Toxicol. 30:1178-1191.

Yang, G., X. Zhou, J. Wang, W. Zhang, H. Zheng, W. Lu, and J. Yuan. 2012. MEHP-induced oxidative DNA damage and apoptosis in HepG2 cells correlates with p53-mediated mitochondriadependent signaling pathway. Food Chem. Toxicol. 50:2424-2431.

Yu, Y., R. Dumollard, A. Rossbach, F. A. Lai, and K. Swann. 2010 Redistribution of mitochondria leads to bursts of ATP production during spontaneous mouse oocyte maturation. J. Cell. Physiol 224:672-680.

Zampolla, T., E. Spikings, D. Rawson, and T. Zhang. 2011. Cytoskeleton proteins $\mathrm{F}$-actin and tubulin distribution and interaction with mitochondria in the granulosa cells surrounding stage III zebrafish (Danio rerio) oocytes. Theriogenology 76:1110-1119.

Zhang, T., L. Li, X. S. Qin, Y. Zhou, X. F. Zhang, L. Q. Wang, M. De Felici, H. Chen, G. Q. Qin, and W. Shen. 2014. Di-(2-ethylhexyl) phthalate and bisphenol A exposure impairs mouse primordial follicle assembly in vitro. Environ. Mol. Mutagen. 55:343-353. 